\title{
How Cities and Regions Can Become Thriving Entrepreneurial Hubs
}

\author{
Ken Harrington (The Bayberry Group)
}

KEYWORDS: Entrepreneurship.

Over the past five to 10 years, cities and regions have steadily worked to create what many call "entrepreneurial ecosystems" that spur innovation economies. As managing director of the Washington University in St. Louis Skandalaris Center for Entrepreneurial Studies from July of 2001 to September of 2014, I've been fortunate to be part of such a transformation. We created a vibrant entrepreneurial community and movement at Wash $\mathrm{U}$, and we also connected the university to what has been recognized as one of the nation's top emerging entrepreneurial communities. I have watched as St. Louis and other regions and universities have evolved to create vibrant innovation economies rooted in entrepreneurial activity.

This commentary is the first of what I hope will be several that will share my observations in a way that may contribute to our collective thinking on this important topic. My intent is to outline the key elements of good "innovation ecosystems," with the hope that this language and framework will contribute to our discussions.

Innovation Support Systems have four groups of factors that, when combined, create vibrant entrepreneurial economies:

- Two groups are social (Social Innovation Factors)

- Two groups are economic (Economic Innovation Factors)

\section{Social Innovation Factors}

These two factors relate to people and how they interact. They rely on relationships and trust, are intangible, may be somewhat invisible, take time to establish, and in the early 2000s were often overlooked by economic development and stakeholder alignment innovation cluster planning efforts.

The Culture Group encompasses informal and formal community-wide factors including associations, collaboration events, community knowledge, media messages, education, mentoring support, education and other social relationship factors. The culture group also includes more individual items that encompass friendships, motivations and values, perceived future rewards or losses, experiences, recognition and other items. Culture activities and events can be consciously engineered to stimulate and energize new relationships. The success and growth of Accelerators (as opposed to Incubators that were more economic and real estate in personality) over the past five years has demonstrated the power of intentionally mixing social factors with only small economic inputs. The Kauffman Foundation One Million Cups initiative is a second example of how increasing entrepreneur relationship adds to the energy of a region. Over time, the advancement of Culture Factors increases a region's Entrepreneurial IQ (EIQ). Higher EIQ gradually adds momentum to a region's ecosystem, and outcomes can be measured in the volume, funding and success of ventures that lead to jobs and economic growth.

The Institution Group includes items that affect the time and effort needed to establish relationships between people when they meet and decide to work on ideas. It includes such items as contracts, idea disclosure formalities, employment agreements, company policies and procedures, investment terms, due diligence, wealth sharing agreements, property rights (IP), conflicts of interest and who takes credit for accomplishments. In the case of universities, technology transfer policies and procedures are a good example of Institutions. The United States is fortunate that its legal system is entrepreneurial friendly. Regulations, local conditions, political and competitive barriers may be factors influencing entrepreneurial activity. Over time, Culture Factors and Higher EIQ have a positive influence on institution factors, and as that happens, ecosystems gain momentum. It becomes easier to get things done, and transactions and partnerships happen 
faster as knowledge and trust increase. Service providers become more entrepreneurially competent, and things seem to happen more quickly and at lower cost.

\section{Economic Innovation Factors}

These factors relate to economic investments and resources. Financial resources are needed to fund Culture programming, but this is usually a minor element when compared to the overall Economic Innovation Factor investments that include funding later-stage ventures, infrastructure, university research and similar items. Economic Factors, other than investments that stimulate Cultural Factors, are tangible.

The Resource Group includes the expenses that fund research and invention, entrepreneur support system programming and individual ventures. It also includes government programs at the national, state, and local levels along with the creation of new venture funds, angel networks, and - in more recent years - larger financial commitments to Social Innovation Factor Program Activity. corporate innovation programs are also a factor, provided a region is vibrant enough to provide valuable innovations or talent that fit a corporation's strategy and personality.

In St. Louis, we discovered that adding support for entrepreneurs at the idea and early phases of entrepreneurial activity were critical to increasing the velocity and level of our EIQ. This caused me to champion this type of investment because it was important as we wrestled over scarce resources, especially when the returns lagged activity. Examples of things that evolved were IdeaBounce events to help connect and get early advice for any type of entrepreneur. We also established volunteer venture mentoring services modeled after the MIT Venture Mentoring Service, and those grew to mid-stage, technology-specific entrepreneur support systems. Weekly and open to anyone, One Million Cups and the recently launched Venture Cafe have increased the velocity and energy, attracting more entrepreneurs and other interested parties. We also held many events, competitions, start-up weekends and meet-up activities.

The Infrastructure Group is made up of capital expenditures. These frequently require large up-front investments. They include buildings, lab facilities, research equipment, coworking space, infrastructure and similar items. In the early 2000s, many of these investments were for real estate that included wet labs and shared facilities such as incubators. In some cases, these were focused on a limited number of "best" ventures. As I observed these nationally, I often saw they were tightly controlled, judgmental ("If your plan is good enough, you will get admitted"), and lackedSocial Factor elements. These efforts did not scale into vibrant, broad-based ecosystems, and they were difficult to sustain economically. Thankfully, this changed dramatically, and we now see higher returns from Infrastructure investments as social factors become a return multiplier by increasing entrepreneurial activity, steadily increasing communities' EIQs, and delivering more funding, successes and jobs.

Overall, I believe that intentionally mixing Social and Economic Innovation Factors is the key to a region's collective EIQ. Higher EIQ adds to the momentum and scaling of entrepreneurial activity and innovation. This yields creative energy, cultural vibrancy, entrepreneurial intention, economic growth, social welfare, wealth, talent and jobs.

This is the first of several commentaries on this topic of entrepreneur ecosystems that I see as support systems that will increase EIQ and entrepreneurial activity. I welcome your thoughts and comments, especially differing points of view or thoughts expanding upon these ideas. Also, please feel free to e-mail me (ken@BayberryGroup.net), or send me a Linkedln invite. Thank you to EIX Exchange for providing a forum for practitioner and scholarly entrepreneurs to meet, share and collaborate on ideas and thinking. 